Portland State University

PDXScholar

$9-2015$

\title{
Document Delivery by the Seat of Your Pants
}

Molly Gunderson

Portland State University, mgun2@pdx.edu

Turner Masland

Portland State University, masland@pdx.edu

Follow this and additional works at: https://pdxscholar.library.pdx.edu/ulib_fac

Part of the Library and Information Science Commons

Let us know how access to this document benefits you.

\section{Citation Details}

Gunderson, M., \& Masland, T. (2015). Document Delivery by the Seat of Your Pants. OLA Quarterly, 21(2), 5-11. http://dx.doi.org/10.7710/1093-7374.1796

This Article is brought to you for free and open access. It has been accepted for inclusion in Library Faculty Publications and Presentations by an authorized administrator of PDXScholar. Please contact us if we can make this document more accessible: pdxscholar@pdx.edu. 


\section{Document Delivery by the Seat of Your Pants}

\section{by Molly Gunderson}

Access Services Manager

Portland State University Library

mgun2@pdx.edu

and

\section{Turner Masland}

Resource Sharing Supervisor Portland State University Library masland@pdx.edu

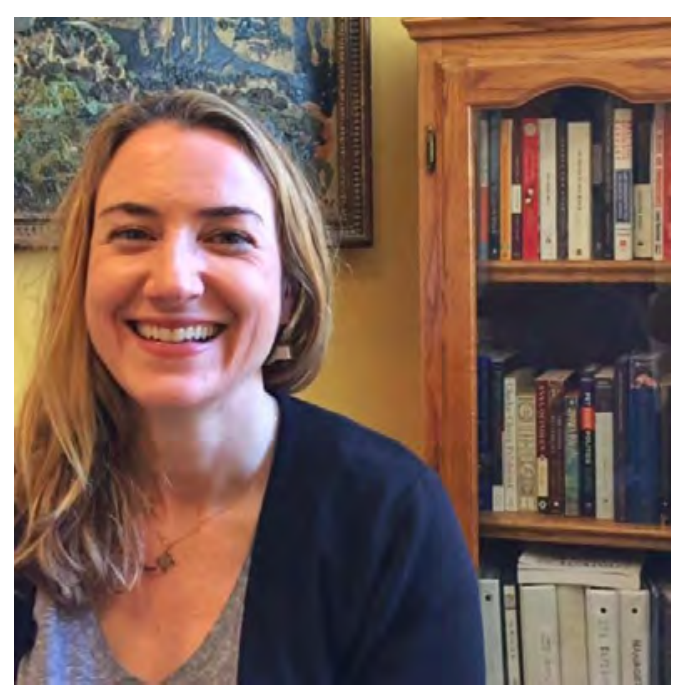

MOLLY GUNDERSON

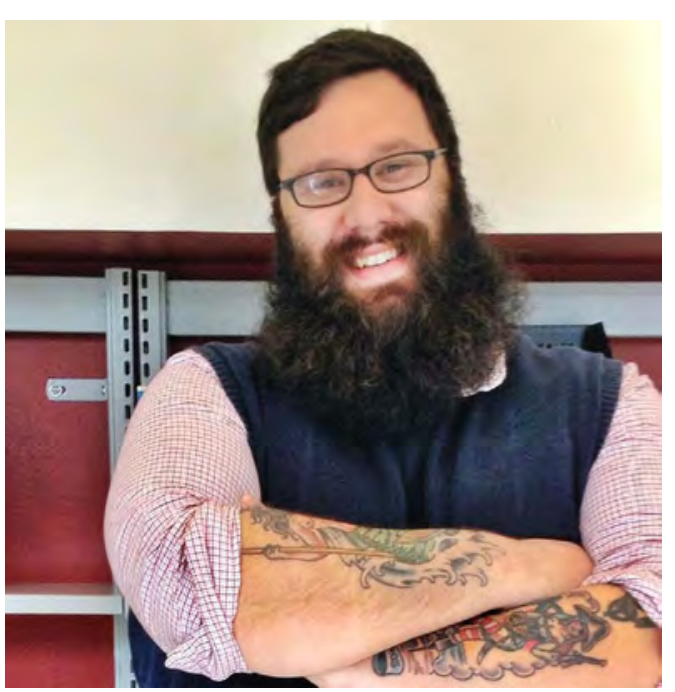

TURner MasLAND

\section{Introduction}

Portland State University (PSU) is the largest university in Oregon with a population of almost 30,000 students. Located in the heart of downtown Portland our campus is woven directly into the fabric of the city. There are many benefits to urban campuses, but one constant challenge is lack of space. As one of the few locations with dedicated study space and collaborative learning, the PSU library is a popular location for students to gather and spend time on campus. Our gate count numbers increase every year and students heavily use our course reserve textbooks, computer labs, laptop checkouts, and practice presentation rooms. However, like many libraries, we found our print circulation numbers going down. At the same time, we were looking for ways to improve services to our patrons. We thought about how we could utilize our large print collection to make it more accessible. In order to maximize space in our main library, many of our journals and books are located in an offsite storage (the Annex) located four miles from the library. The Annex holds about one third of our collection. If patrons needed a journal article, the wait could be anywhere from 13 days. There was a great deal of schlepping back and forth between the Annex and the PSU Library. First, patrons would request the journal article, then the library staff would retrieve the entire journal from the Annex and bring it back. The patron would have to come to the library to scan or photocopy the article. Finally, when the patron was done the staff person would take the journal back to the Annex.

We wanted to eliminate the number of steps involved and get the article into the hands of the patron within 24 hours. We worked with our Library Technologies team to purchase and install a Scannex scanner out in the storage facility. Because we call the storage facil- 
ity "The Annex" we jokingly referred to it as "The Scannex in the Annex." With the new scanner, we could scan the journal article and email it to the patron right away. The whole process took about 15 minutes, greatly reducing the turnaround time. Developing a document delivery service allowed us to provide excellent customer service while we continue to transition lesser user collection materials to offsite storage.

Our goal in writing this article is to share how we developed this service. We talk about the implementation of the service: from choosing software platforms and scanning hardware to deciding on document delivery policies and marketing strategies. We then will share some usage statistics and provide insights into who the users of this service are and how they are using it. We will also provide some testimonials from faculty who are using the service. With our conclusion we will share how we have benefited from this service and and include our suggestions for other libraries who are considering implementing a similar service.

\section{Implementation}

Implementing a document delivery service was comprised of the following steps: designing workflows for our staff, shaping policies to guide the service, deciding on the best scanning hardware to meet our needs and marketing the service. We wanted a service that would be relatively easy to roll out without having to learn new systems. At the time of development we knew that we would soon be migrating to the Orbis Cascade shared integrated library system. Knowing how much work that would involve, we needed a simple solution for this new service. The following section will describe our decision making during the implementation process.

In designing our workflow, we started determining what platform would be best for supporting our document delivery service. We were already using ILLiad for our interlibrary loan services, making the platform a natural fit for document delivery. Essentially, document delivery would be an extension of the work we were already doing. Previous to rolling out document delivery, the Interlibrary Loan Office would receive many requests for articles found in journals we owned physically. Previously, we would cancel these requests with instructions on how to find the articles in our collection. The intention was to encourage patrons to access these materials on their own. With the advent of document delivery, and the emphasis we were placing on customer service, we would simply process the request: scanning and delivering the article. Because we were already using ILLiad, it would be easy to adopt interlibrary loan workflows for our document delivery service. For example, we would print pull slips for both document delivery and interlibrary loan congruently, and these slips could be given to staff either in our main library or to be brought out to the Annex. This was a similar process that was already in effect for interlibrary loan. The major difference would be the scanning of material at the Annex, saving our storage staff time and energy of transporting material between locations. The additional benefit of ILLiad was the automation of patron notifications, which were built in to the workflow of processing requests. It would not require any extra work to inform our patrons on the status of their requests. And these requests could be managed in their interlibrary loan accounts, allowing for a central location for patrons to view all of their current library requests. Given all of these factors: use of ILLiad by the Interlibrary Loan Office; automation of workflows, delivery and notification; and centralization of patron library requests: ILLiad was our document delivery platform of choice.

The next step towards implementing a document delivery service was shaping our policy. There were some important questions we needed to answer. What would we scan? Who would be eligible for this service? How long should our patrons expect to wait? In 
terms of what we would deliver, we started only with journal articles, to determine work load and decide later if we would include other material (such as book chapters or microform). We limited each request to one article per journal. If patrons needed more than one article, or if the article was longer than fifty pages, we would pull the journal and place it on the hold shelf for the patron. Our service would be open to all currently enrolled students and all faculty and staff. Due to our large patron base, we are not able to open the service up to community users and alumni. However, we are certainly willing to pull physical material from the Annex for our community users and alumni. We advertise our turnaround time as being 24-72 hours. Realistically, we are able to process document delivery requests within 24 hours, if not the same day we receive the request. But advertising a 23 day turnaround time accounts for instances when we might be short staffed, or our systems being down, or for another unpredictable barrier of service that might (and probably will) occur.

As mentioned in the introduction, a major motivating factor for providing a document delivery was an attempt to make materials stored in the Annex more accessible for our patrons. This factor played a huge role in designing our workflow, specifically in regards to what scanning hardware we wanted in the Annex. At the time of implementing this service: the Public Access Services department was managing two different scanners: BScan for interlibrary loan services and Scannex for public use. The BScan has many benefits: it is hardware that has been developed and marketed for interlibrary loan services. However, it takes a lot of training to learn how to use properly. As we mentioned earlier, we needed a fast and simple roll out. Scannex scanners are incredibly user friendly, and the accompanying platform allowed us to easily integrate the scanner into our ILLiad workflows. Much like ILLiad being our logical choice for a document delivery platform, Scannex scanners were are logical choice for our storage facilities scanning hardware.

The final step in our implementation process was deciding on how we were going to market the document delivery service as we rolled it out. At first, we didn't market it at all. We simply began to process all interlibrary loan requests for articles found in journals we owned as document delivery requests. This was a change to our previous policy of simply canceling requests. This allowed for beta testing, making sure all of our systems were working as expected. From there we marketed first to campus faculty members, who were very pleased with the service. This new system was communicated through our liaison librarians, who already had working relationships with teaching and research faculty. From there, we marketed document delivery through traditional means: setting up a page on the library's website, announcing it through social media, and continuing to work with liaison and reference librarians to promote the services.

\section{Use Statistics}

The following section will highlight document delivery use statistics in an attempt to provide insight in how our patrons are using our services and who our users are. We will provide insight into how these statistics were collected and provide insights into what we feel these numbers tell us. It's important to note that this is a casual assessment and we are providing anecdotal evidence. In our conclusion we will talk about a need for a more indepth and scientific assessment of this service.

We would like to start by providing how we obtained these statistics. We used ILLiad's Custom Request Search function to gather these numbers. Our search criteria was limited to Transaction Status (Request Finished), Process Type (Document Delivery), Request Type 
(Article) and Creation Date (between July 1, 2013 to June 30, 2014 or July 1, 2014 to June $30,2015)$. We used creation date as our criteria for the time frame because we wanted to capture when the patron was interacting with the service, rather than when the staff were processing the service (which would have been Transaction Date). We limited the Request Type because purchase requests that are submitted through ILLiad import as Loans, and we wanted to be sure we were only capturing material we were providing our patrons digitally. And we only wanted to look at the Transaction Status because we wanted to look at material we successfully provided our patrons.

Table 1: Total Requests

\begin{tabular}{|l|l|}
\hline 2013-2014 & $\mathbf{2 0 1 4 - 2 0 1 5}$ \\
\hline Total Requests: 1884 & Total Requests: 1049 \\
\hline Total Number of Patrons: 827 & Total Number of Patrons: 487 \\
\hline
\end{tabular}

The first set of numbers we looked at were the total number of document delivery requests that were successfully completed and the total number of patrons. As you can see in Table 1, about there was a drop of about 44 percent of total requests placed and a drop of about 41 percent total number of patrons using the service in 2014-2015 versus 2013-2014. The biggest change in the library's operation that could have affected this major drop was a migration from WorldCat Local as our primary discovery layer to Ex Libris' Primo discovery layer. We feel there are two possible reasons this migration caused this drop in numbers.

The first possible explanation is that our patrons were better able to find what they were looking for with the Primo discovery layer. Primo allows our users to conduct a much more granulated, article level search with relevant hits appearing higher in their patron's search results. Portland State University has also been making a concerted effort to provide item level holdings of our serials, both physical and electronic, which provides our users with a more accurate picture of what is owned locally. These factors could mean that users are better able to find locally held material, especially of electronic material, and thus they do not need to use the document delivery service. When they are not able to access their desired articles, those requests are processed through interlibrary loan.

The second possible explanation for this drop is that users found Primo to be a barrier of service and thus simply placed fewer requests. Anecdotal evidence to support this claim starts with the fact that many of our power researchers (including faculty and graduate students) were really frustrated with the switch from WorldCat Local to Primo and might have sought out other sources for their research needs. Additionally, the Public Access Services department saw our Summit consortial borrowing numbers dropped by roughly 33 percent and our interlibrary loan numbers dropped by roughly 40 percent. We know that the Summit system had a login process that was not user friendly. Before all Orbis Cascade Alliance Libraries migrated to the Ex Libris system, library patrons had to log into multiple systems (first Ex Libris' system and then OCLC's system) to successfully request Summit material. These multiple authentications were frustrating at worst, irritating at best. Interlibrary loan numbers might have dropped because the total number of bibliographic records in Primo is much smaller compared to the number of records found in WorldCat. 
Perhaps if our users were experiencing barriers of service for Summit and interlibrary loan, it's certainly logical to believe that they experience barriers of service for placing document delivery requests as well.

Again, understanding the real reason why these numbers dropped would take a more indepth examination of our user's information searching behavior. While we only have a cursory understanding of why these numbers dropped, we do know that they definitely decreased.

Table 2: Physical Location of Requested Articles

\begin{tabular}{|l|l|}
\hline 2013-2014 & 2014-2015 \\
\hline Main Library: 968 & Main Library: 724 \\
\hline The Annex: 325 & The Annex: 297 \\
\hline Other: 591 & Other: 23 \\
\hline
\end{tabular}

Since a major motivating factor for implementing a document delivery service was to better connect our patron with the collection that is housed in the Annex, our second set of numbers looks at where the requested material lives within our collection. As mentioned in the previous section, we saw a drop in usage of the services between the two years it has been operating. What is interesting here is the fact that requested material from the main library dropped roughly 25 percent whereas requested material that lives in the Annex dropped only about 10 percent. We feel that this shows the use of the service to request articles from our offsite facility remained relatively stable compared to the use of the system as a whole.

The other important note is that the "Other" category dropped significantly. These requests did not have any location information, which is provided by the staff or student workers who were processing the requests. The sharp decrease in number indicates that staff are much more effective in processing these requests.

The third set of numbers we looked at provided insight into who were using this service. Not surprisingly, it was our graduate students, followed by our faculty. These two groups are conducting a significant percentage of research activity on campus. As we continue to provide this service we hope to see more distance users take advantage of document delivery, as it is an efficient way to connect these users with our library materials.

(See Table 3 next page.)

Finally, we looked at the top ten departments represented by our users. Our top users have consistently been associated with the sciences and social sciences. This makes sense, as these disciplines traditionally use timely articles as their primary research material, due to an articles ability to represent current scholarly communication, whereas the arts and humanities are using primary sources as common materials in their research. (See Table 4 next page.)

We look forward to collecting additional use statistics as we continue to provide these services. We hope to further understand how our patrons interact with this service so we can strive to best meet their needs. 
Table 3: Use by Patron Status

\begin{tabular}{|l|l|}
\hline $2013-2014$ & $2014-2015$ \\
\hline Emeritus: 11 & Emeritus: 0 \\
\hline Faculty: 391 & Faculty: 233 \\
\hline Faculty Distance: 8 & Faculty Distance: 7 \\
\hline Faculty Visiting: 2 & Faculty Visiting: 0 \\
\hline Grad: 926 & Grad: 217 \\
\hline Grad Distance: 97 & Grad Distance: 24 \\
\hline High school: 0 & High school: 1 \\
\hline Honors: 7 & Honors: 23 \\
\hline Staff: 36 & Staff: 36 \\
\hline Staff Distance: 1 & Staff Distance: 1 \\
\hline Undergrad: 360 & Undergrad: 121 \\
\hline Undergrad Distance: 14 & Undergrad Distance: 4 \\
\hline
\end{tabular}

Table 4: Top Ten Departments

\begin{tabular}{|l|l|}
\hline 2013-2014 & $\mathbf{2 0 1 4 - 2 0 1 5}$ \\
\hline Biology: 146 requests & Engineering: 151 requests \\
\hline Social Work: 139 requests & Biology: 98 requests \\
\hline Psychology: 138 requests & English: 86 requests \\
\hline Chemistry: 125 requests & Chemistry: 85 requests \\
\hline Engineering: 119 requests & Physics: 61 requests \\
\hline Graduate School of Education: 96 requests & Social Work: 55 requests \\
\hline Environmental Science: 83 requests & Education: 47 requests \\
\hline Urban Studies \& Planning: 81 requests & Psychology: 40 requests \\
\hline Architecture: 79 requests & Environmental Science: 36 requests \\
\hline English: 66 requests & Urban Studies \& Planning: 35 requests \\
\hline
\end{tabular}




\section{Faculty Delivery Testimonials}

In September of 2014, at the Northwest Interlibrary Loan conference we presented how we implemented our document delivery service. Included in that presentation were testimonials we gathered from PSU faculty, illuminating their experiences with this service. We feel these testimonials are worth including here, to provide a wider lense than just the numbers provide:

"I greatly appreciate the delivery service. I have developed some physical disability issues that have made it difficult for me to get to the library. I am grateful for the service! Keep up the good work!"

"This is so great! It would also be terrific to have some kind of pickup at departments.

Thank you so much for doing this and for all your help!"

"Love it! This saves so much time and makes me feel as if my work is valued and supported."

\section{Conclusion}

While it is apparent that our use numbers have fluctuated, our faculty testimonials have given us confidence that document delivery has been a welcome addition to the PSU library's service toolbox. Document delivery allows library staff to quickly provide electronic copies of articles and book chapters to our patrons, saving them time. By installing the scanner in the Annex, the number of materials that need to be physically transported between locations has decreased dramatically, saving the time and energy of our staff members.

If you are considering implementing a similar service, our biggest recommendation is to make sure that you have an appropriate level of staff who will be able to handle the scanning that will be involved. Here at PSU we had to increase our student worker hours by about 20 hours a week to process these requests. Also, you want to be sure that you find the right platform and hardware to best meet your needs. At PSU, ILLiad made the most sense as our platform, as it was one we were already utilizing for our interlibrary loan services. We found the Scannex scanners to be the most user friendly in our Annex, but there are certainly other options available that might best meet your library's unique needs. An additional consideration is how you will present this service both on your website and within your online catalog/discovery layer. If the patrons are unable to find the service, then they are not going to be able to use it. We have included a link to both interlibrary loan and document delivery on every item record that is not available online in full text. Along these same lines, we want to encourage libraries to have an aggressive marketing campaign, to let users know about your document delivery service.

Rolling out this service took a considerable amount of work, from planning and troubleshooting the service to raising awareness about its usefulness, but we feel that the time and energy it took to implement it was well worth it. If you think that this is a service that you would like to provide your patrons, we highly encourage you to move forward with it and we will be more than happy to further share our experience getting it off the ground. 